\title{
Pseudoxanthoma elasticum: An unusual case of gastrointestinal bleeding
}

\author{
Deborah J. COOK, MD, FRCPC, SAmIH S. SALAma, MB, ChB, FRCPC, ROBERT J. TUTTLE, MD, FRCPC
}

ABSTRACT: Pseudoxanthoma elasticum (PXE) is an inherited disorder of connective tissue, characterized by calcification and degeneration of elastin. Clinical manifestations of PXE are protean, with skin, eyes and arteries being most commonly involved. Although often a benign condition, gastrointestinal hemorrhage is a potentially fatal complication. An unusual case of gastrointestinal hemorrhage in a patient with PXE is described and the pathophysiology, clinical presentation and complications of this rare condition are reviewed. Can J Gastroenterol 1989;3(4):141-144

Key Words: Connective tissue disease, Gastrointestinal hemorrhage, Pseudoxanthoma elasticum

\section{Pseudoxhantome élastique: Un cas inhabituel d'hémorragie gastrointestinale}

RESUME: Le pseudoxhantome élastique (PXE) est une hérédopathie des tissus conjonctifs caractérisée par la calcification et la dégénérescence de l'élastine. Les maniféstations clinique du PXE sont changeantes mais touchent le plus souvent la peau, les yeux et les artères. Bien que la condition soit bénigne, l'hémorragie gastrointestinale est une complication fatale possible. Nous décrivons le cas inhabituel d'une hémorragie gastrointestinale survenue chez un patient atteint de PXE et passons en revue la physiopathologie, le tableau clinique et les complications de cette condition rare.

Departments of Medicine, Pathology and Radiology, St Joseph's Hospital; and McMaster University, Hamilton, Ontario

Correspondence: Dr D.J. Cook, Department of Internal Medicine, Room 1B7, McMaster University Hospital, 1200 Main Street West, Hamilton, Ontario L8N 325. Telephone (416) $521-2100$

Received for publication December 1988. Accepted May 8, 1989
A 36-YEAR-OLD MAN PRESENTED WITH a two day history of hematemesis and melena. He had no previous peptic ulcer disease or alcoholism.

On examination, blood pressure was $90 / 50 \mathrm{mmHg}$ with a heart rate of 120 beats/min. Mild epigastric tenderness was noted but there was no stigmata of chronic liver disease. Peripheral pulses below the popliteal were not palpable. Fundoscopy revealed bilateral grey streaks radiating from the optic discs (Figure 1).

The initial hemoglobin was $85 \mathrm{~g} / \mathrm{L}$ with a mean corpuscular volume of $88 \mathrm{fL}$. The platelet count, prothrombin time, partial thromboplastin time and thrombin clotting time were normal.

Endoscopy revealed diffuse gastritis. Red blood cells, crystalloid and histamine antagonists were administered. During insertion of a central venous catheter, multiple yellow papules and redundant folds of skin were noted in the neck (Figure 2). Hematemesis and hypotension persisted. Repeat endoscopy failed to disclose a distinct bleeding site. Celiac arteriography demonstrated 


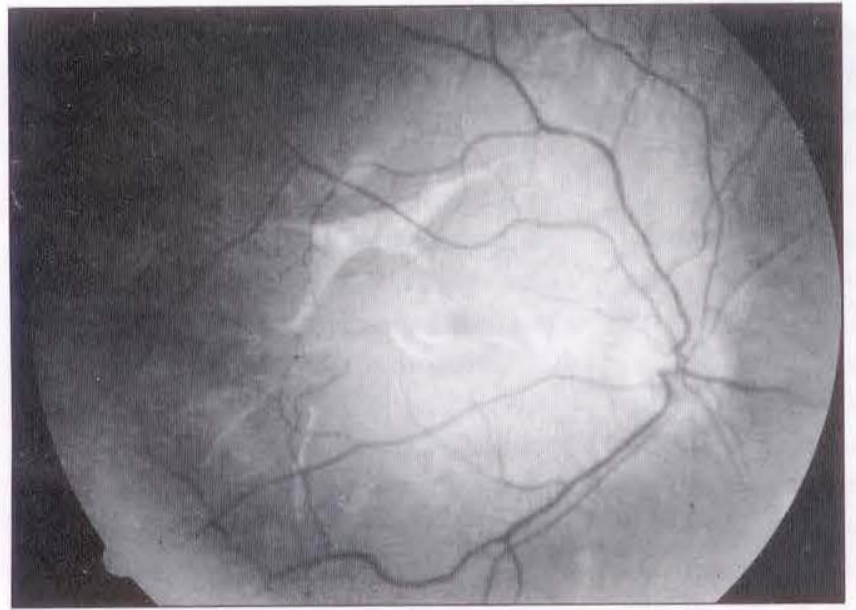

Figure 1) Fluorescein angiography of left fundus showing radiating streaks of hyperfluorescence around the disc, characteristic of angioid streaks

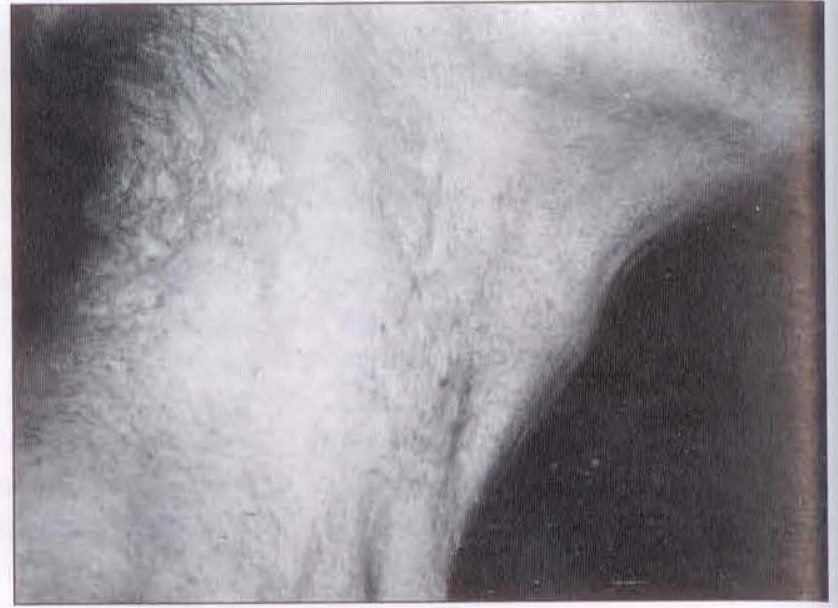

Figure 2)Typical yellow papular lesions on the neck

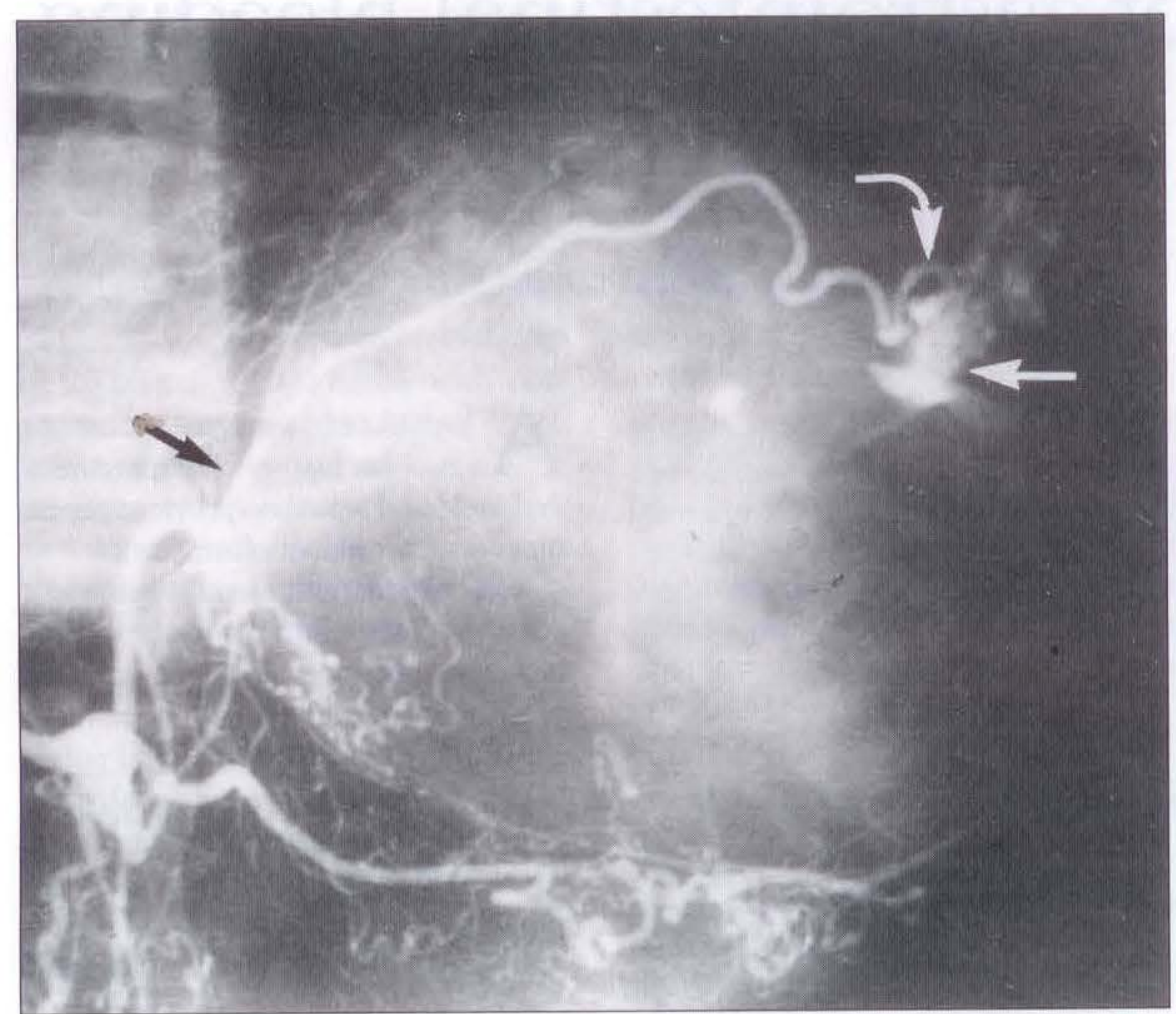

Figure 3) Hypertrophied left gastric artery (dark arrow), vascular malformation (curved arrow) and contrast extravasation (white arrow)

an actively bleeding arteriovenous malformation arising from the left gastric artery (Figure 3 ). The patient underwent proximal gastrectomy and an uneventful recovery ensued.

Postoperatively, the serum alkaline phosphatase was elevated at $280 \mathrm{iu} / \mathrm{L}$, although the serum calcium, phosphate, aspartate aminotransferase, ure 4) revealed large arterial vessels within the submucosa, with marked subintimal elastosis, subintimal fibrosis and calcified fragmented elastic lamina. These vascular abnormalities, found in the serosa and omental fat, were consistent with pseudoxanthoma elasticum. A skin biopsy was performed which confirmed this diagnosis.

\section{DISCUSSION}

The cause of acute gastrointestinal bleeding may evade diagnosis in 10 to $20 \%$ of cases (1). Several muco. cutaneous disorders, including PeutzJeghers syndrome, Rendu-Osler-Weber syndrome, Kaposi's sarcoma, Ehlers Danlos syndrome, as well as pseudoxan. thoma elasticum, should be considered in cases of gastrointestinal hemorrhage of obscure origin. The estimated prevalence of PXE ranges from one in 160,000 to one in $1,000,000$ (2). How. ever, the reported incidence of gastrointestinal hemorrhage in this condition is $13 \%$ (3).

Gastroscopic findings in asymptomatic patients with PXE include gastritis and yellow submucosal lesions which may ulcerate (4). During acute bleed. ing, angiography has demonstrated tortuous vessels and microaneurysms in several different sites simultaneously (5). Degenerative vascular elastin may predispose to vessel rupture (6) or may inhibit vessel constriction, and thereby prevent shunting of blood away from the mucosa during hemorrhage (4). 

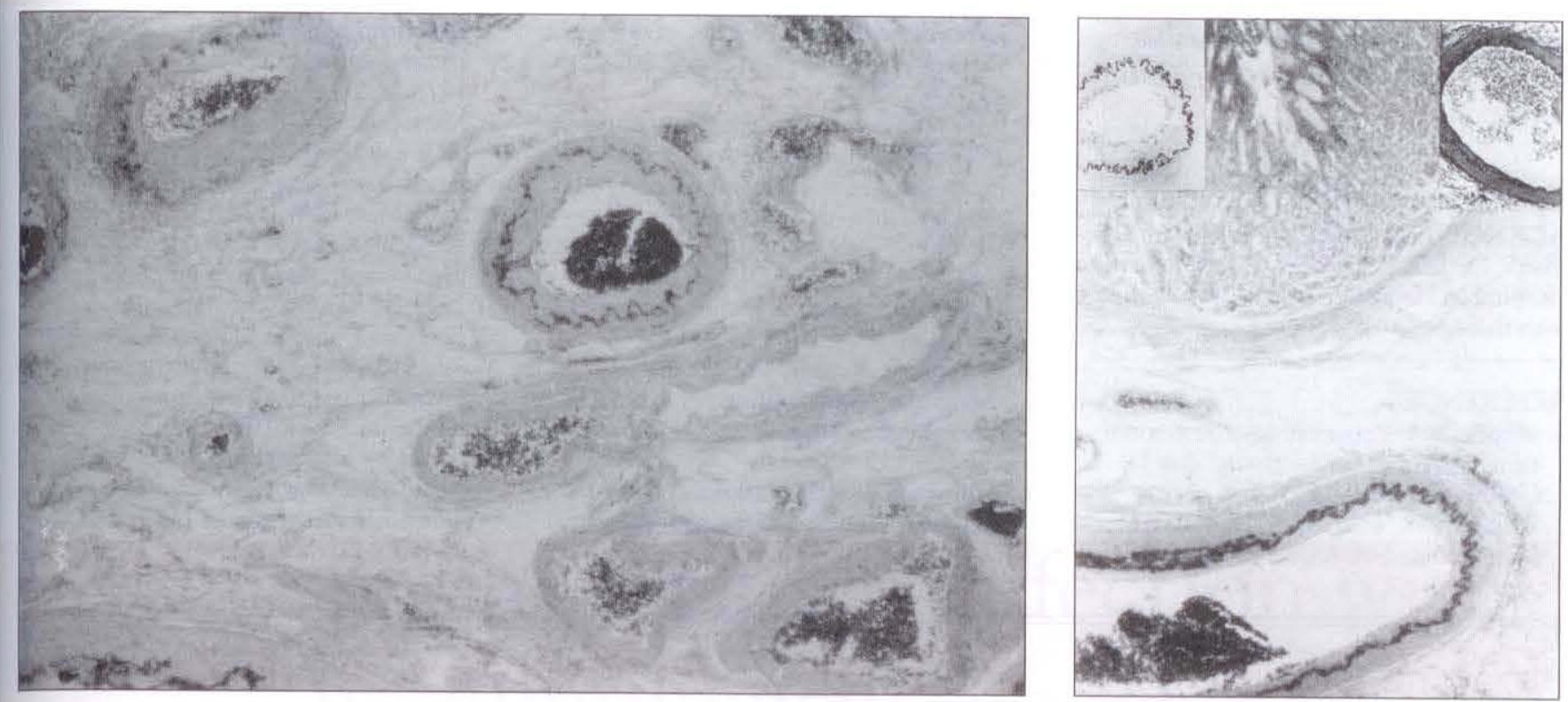

Figure 4) A Submucosal gastric arterial vessel showing markedly thickened wavy internal elastic lamina. B Low power microscopic view of abnormally large submucosal gastric arterial vessels with calcified, thickened internal elastic lamina. Inset in upper left shous calcified deposits (Von Kossa stain). Inset in upper right shows markedly thickened internal elastic lamina (Miller elastic stain)

In this patient, PXE was suggested by identification of characteristic cutaneous lesions. Retrospectively, angioid streaks and subsequently, dermal and gastrointestinal vascular pathology confirmed the diagnosis.

Skin lesions in PXE consist of yellow xanthoma-like papules in the neck, axilla, antecubital and popliteal fossae and inguinal creases, giving the skin a 'peau d'orange' or 'plucked chicken' appearance (7).

The association of these cutaneous markings and angioid streaks is called the Groenblad-Strandberg syndrome. Brown or grey angioid streaks radiating out from the optic disc may be present in more than $80 \%$ of cases of PXE (1). Frequently misinterpreted as retinal vessels, they represent breaks in the elastic tissue of Bruch's membrane, permitting visualization of choroidal pigment. However, angioid streaks are not specific for PXE: other associated conditions include sickle cell anemia, Ehlers Danlos, hyperphosphatemia, lead poisoning and Paget's disease (7). In the present patient, the angioid streaks, increased alkaline phosphatase and arterial calcification were compatible with Paget's disease, however, urinary hydroxyproline and $\mathrm{x}$-rays were not diagnostic.
Vascular involvement in PXE includes severe atherosclerosis, hypertension and asymptomatic occlusion of the ulnar and radial arteries (6). Premature peripheral vascular disease can cause debilitating claudication and cerebrovascular infarcts; aneurysms may predispose to subarachnoid hemorrhage (7). Coronary artery disease is found with increased frequency (8) and sudden death has been reported in three children with PXE due to myocardial infarction (9). The specific cardiovascular manifestation of PXE is characterized by intimal fibroelasic thickening, with fragmentation and calcification of the deep endocardium. Diffuse endocardial fibroelastosis may mimic restrictive cardiomyopathy (10) or cause congestive cardiomyopathy (8).

There are four genetically distinct patients with PXE (11). The dominant type 1 group show the typical flexural 'peau d'orange' rash, the most severe retinopathy and vascular disease. In contrast, the more common dominant type 2 group have either grossly normal skin or a mild yellow macular rash in $70 \%$ of cases. Vascular and retinal disease is minimal. In the recessive type 1 variant, $77 \%$ show the classical flexurally distributed lesions and gastrointestinal bleeding is common.
The recessive type 2 variant is the rarest, characterized by marked skin changes only.

Screening of unaffected relatives is not warranted; early detection of PXE may factitiously improve survival due to lead time bias but is unlikely to change outcome. However, in view of the vascular abnormalities and potential for massive gastrointestinal hemorrhage, elective endoscopy and aggressive treatment of gastritis, if present, have been suggested (7).

Anecdotal reports exist of ocular and dermatologic improvement with vitamin $E$ therapy or calcium restriction (9). However, specific treatment for PXE is unavailable. Therefore, management is directed at genetic counselling, controlling risk factors for atherosclerosis and gastrointestinal bleeding, and treating complications.

The importance of dermatologic and fundoscopic examination in patients with gastrointestinal bleeding of unknown etiology is highlighted by this unusual case of pseudoxanthoma elasticum involving the gastrointestinal tract. Although the most common manifestations of PXE are dermatologi$\mathrm{cal}$, the initial presentation may involve other organ systems, suggesting the need for many specialists to be 
aware of the potentially devastating hemodynamic consequences of this condition.

ACKNOWLEDGEMENTS: The authors thank Dr W.M. Goldberg of St Joseph's Hospital in Hamilton, Ontario for his help with this case.

\section{REFERENCES}

1. Morgan AA. Recurrent gastrointestinal hemorrhage: An unusual case. Am J Gastroenterol 1982;77:925-8.

2. Schaber DC, Wingfield CD, Maxfield JL. Groenblad-Strandberg syndrome:
Report of a case and review of the literature. J Am Optom Assoc 1980;79:326-31.

3. Eddy DD, Farber EM. Pseudoxanthoma elasticum: Internal manifestations. A report of cases and a statistical review of the literature. Arch Dermatol 1962;86:729-40.

4. Cocco AE, Grayer DI, Walker BA, et al. The stomach in pseudoxanthoma elasticum. JAMA 1969;210:2381-2.

5. Bardsley JL, Koehler PR. Pseudoxanthoma elasticum: Angiographic manifestation in abdominal vessels. Radiology 1969;93:559-62.

6. Polinger IJ. Pseudoxanthoma elasticum and gastrointestinal bleeding. J Maine Med Assoc 1967;58:76-7.
7. Engelman MW, Fliegelman MT. Pseudoxanthoma elasticum. Cutis 1978;21:837-40.

8. Mendelsohn G, Bulkley BH, Hutchins GM. Cardiovascular manifestation of pseudoxanthoma elasticum. Arch Pathol Lab Med 1978;102:298-302.

9. Wilhelm K, Paver K. Sudden death in pseudoxanthoma elasticum. Med J Aust 1972;2:1363-5.

10. Navarro-Lopez F, Llorian A, FerrerRoca O, et al. Restrictive cardiomyopathy in pseudoxanthoma elasticum. Chest 1980;78:113-5.

11. Pope FM. Historical evidence for the genetic heterogeneity of pseudoxanthoma elasticum. Br J Dermatol 1975;92:493-509. 


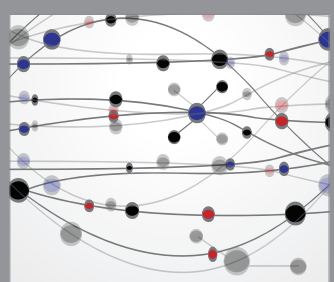

The Scientific World Journal
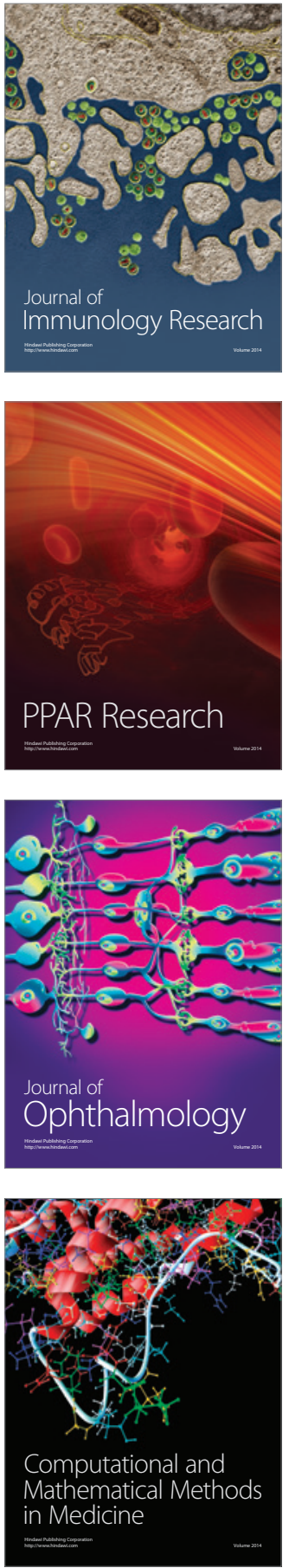

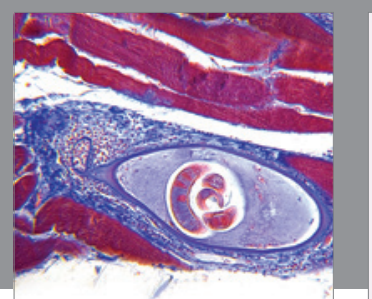

Gastroenterology Research and Practice

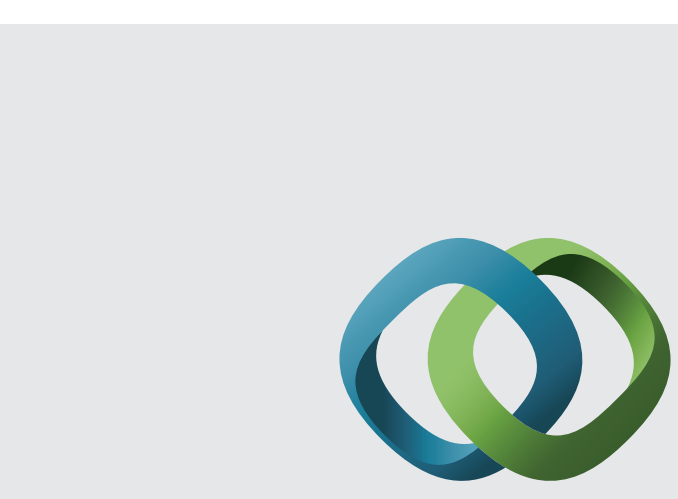

\section{Hindawi}

Submit your manuscripts at

http://www.hindawi.com
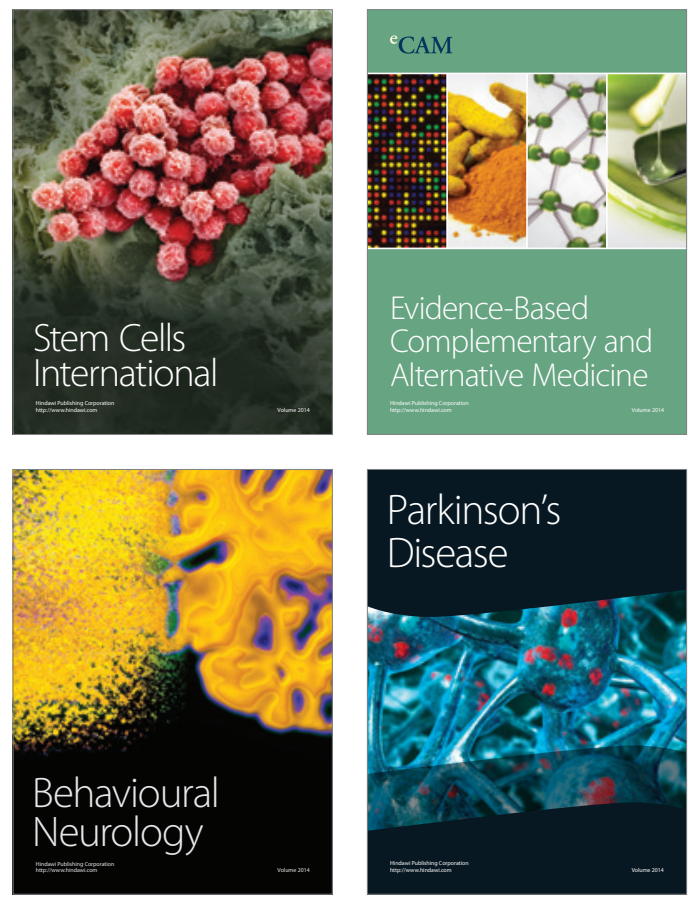
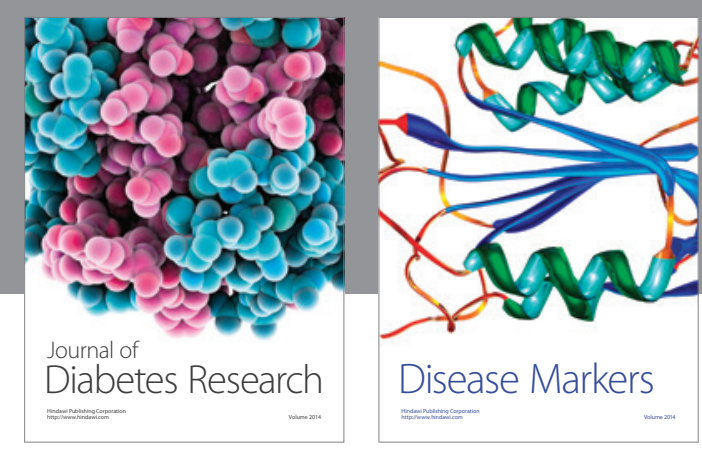

Disease Markers
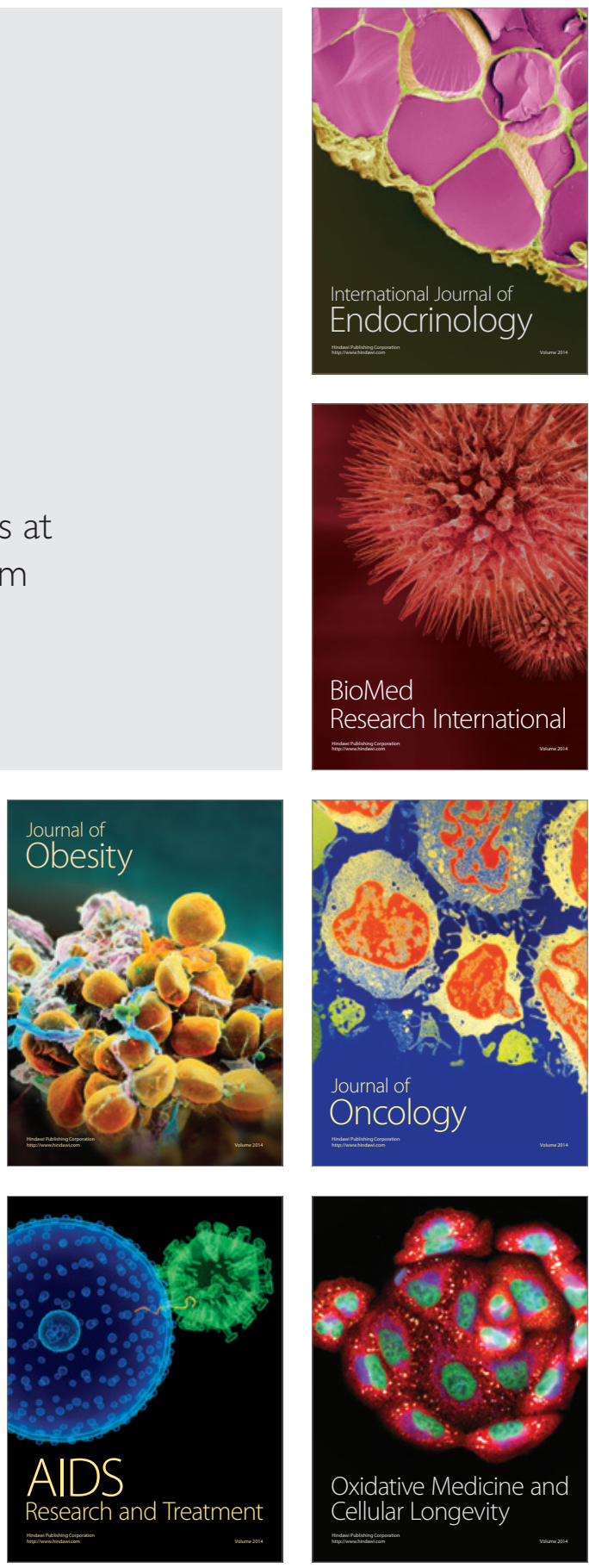